\title{
THE WORK OF THE KENYA MOBILE EYE UNIT* $\dagger$ WITH CLINICAL OBSERVATIONS ON SOME COMMON EYE DISEASES
}

BY

W. R. BURKITT, M.B., B.ch.

Kenya Society for the Blind, Nairobi, Kenya

THIS Unit has now been at work in Kenya for 3 years. It first took to the road in June, 1963, under the auspices of the Kenya Society for the Blind, the African Medical and Research Foundation, the Royal Commonwealth Society for the Blind, and the Kenya Government. It is staffed by a doctor, a Clinical Assistant, a second assistant, and a driver. The assistant staff travel in a long wheel-base land rover, which also carries camping equipment, operating equipment, and drugs. The Medical Officer travels in his own car. The Government provides the salary of the clinical assistant; otherwise financial support is derived from private sources, channelled through the Kenya Society for the Blind and the African Medical and Research Foundation.

The Unit, based on the eye department of the Kenyatta National Hospital, Nairobi, spends as a rule 2 weeks of each month on safari, and usually visits three medical centres. Preparation and publicity are, of course, all-important. There are, at the time of writing, in various parts of Kenya, five medical assistants with ophthalmic training whom we visit regularly. These men, under the Medical Officer of Health for the area, are largely responsible for local publicity and for detailed preparation for the Unit's visit. The medical centres visited are normally the health centres, each with a number of beds where these medical assistants are stationed: Here the Unit holds clinics and operates. The Unit may also hold clinics at other dispensaries or health centres in the area, but cases requiring operation are brought to the central health centre. Some mission and government hospitals are included in our programme, provided they can spare the beds to permit us to operate on cataracts.

It will be helpful to describe a routine safari. The Unit Land Rover, having been packed up on the Saturday morning, leaves for its destination on Monday. Most of the places visited by us lie between 100 and 300 miles from Nairobi, so that the first day is usually occupied in travelling and settling down at the other end. Sometimes empty accommodation is available for the assistant staff; otherwise they erect their own tent and camp; in any case they are responsible for their own cooking, which is carried out by the driver. The first day of the visit is occupied in holding a clinic. A room is chosen and partially darkened with blankets. A torch is used for external examination of the eye and the fundus is examined briefly as a routine. A corneal loupe is used from time to time, but no slit lamp is available. Refractions are only carried out occasionally when time and facilities allow; the visual acuity is estimated where specially indicated, and those cases

* Received for publication March 8, 1967.

$\uparrow$ Address for reprints: Kenya Society for the Blind, P.O. Box 6656, Nairobi, Kenya. 
clearly requiring refraction are referred to Nairobi or some other centre. During a normal working day an average of eighty to 120 patients will be seen, though the number varies greatly depending on local response. Persons with mature cataract or entropion or requiring optical iridectomy are admitted or are requested to return the next day.

Presbyopic patients are supplied with second-hand spectacles at a low price; prescription is carried out on a subjective basis after examination of the fundi; all for whom there is no specific treatment receive a placebo in the form of one application of oculentum achromycin. The majority of patients fall into this latter category, having nothing wrong with them, or having either early cataracts or healed corneal lesions. All treatment is free except for the provision of reading glasses.

Before the day ends preparation is made for the morrow. A suitable room is prepared for the operating session; beds and mattresses, if not already provided, must be fetched from the district hospital; instructions must be given to the local staff in regard to facewashing for the cataracts and the necessary pre-operative eyedrops.

Cutting instruments are sterilized in pure Dettol and other instruments boiled in a small Afrigas sterilizer. Light is provided by a powerful headlamp fed from the Land Rover battery. Anaesthesia is local, plus $100 \mathrm{mg}$. pethidine injection in the case of cataracts; this anaesthesia proves ideal in the case of unimaginative elderly country folk. The smoothness of the day's work will depend on the degree of local co-operation; but if local staff are short our driver turns his hand to being nurse or theatre orderly. In the course of the day we may operate on as many as ten or even twelve cataracts.

For cataracts, the normal method is a limbal-based conjunctival flap, a single corneoscleral suture, peripheral iridectomy, and intracapsular extraction with Arruga's forceps. Probably in practice about 70 per cent. of cases turn out to be intracapsular and 30 per cent. extracapsular.

Nursing facilities under health centre conditions are confined to the simplest patient care; a further problem is that the average country person has little conception of obeying rules, and instructions to remain in bed are likely to be followed for only the first 5 minutes after they are given. Under these circumstances, it is surprising how few complications are seen. We try to arrange for the cataract patients to remain in the health centre for 7 days. A simple form of instruction on post-operative follow-up is given to the Medical Assistant in charge, and on the last morning of the visit all cataracts operated on are dressed by the local Medical Assistant, with the doctor or Clinical Assistant in attendance. Inevitably, on our subsequent visits we see only a proportion of those operated on, but a great majority of those we do see show satisfactory results. It must be noted in this connexion that at present a majority of our cataract patients are simple, elderly illiterates, who require little more than to find their way about, so that even if an operation is a partial failure, the patient will have benefited. If it is a success the patient should see at least $3 / 60$ without glasses. If a patient asks for cataract glasses we can supply them at a cost of $30 s$.

Unsatisfactory as this whole procedure may appear to the orthodox clinician, there is, in fact, no alternative in Kenya at present. There are about sixty government ophthalmic beds in the country for $9,000,000$ people and a waiting list of many months; cataracts are, of course, operated on privately and by mission doctors, but in a developing country some such programme as we have evolved for dealing with senile cataracts is a worthwhile contribution to the problem. 
To return to our operating list-in addition to the cataracts, there may be one optical iridectomy and almost certainly some cases of entropion. For the latter we practise the modified Snellen operation. If time does not allow us to operate on all those who present themselves, our local eye-trained Medical Assistant takes a list of the names and asks those who remain to return at a later date, and he will operate on them himself when the Mobile Eye Unit has left. These Assistants have been trained by us in Nairobi to carry out the modified Snellen procedure, and have been supplied by the Kenya Society for the Blind with a set of the necessary instruments.

Before the Unit leaves the area it is usual for us to carry out some school surveys for trachoma. The incidence of trachoma in the area is best determined by examining the tarsal plates of children in the lowest primary school forms for it is in these that trachoma is most likely to be found. Simple but careful naked-eye examination in a good light, usually out of doors, is carried out on the basis of MacCallan's classification; a list of those with acute trachoma is kept by the head teacher and sufficient Achromycin ointment is left for the teacher to carry on with treatment. The Medical Assistant has also been given training in making trachoma surveys and it is his duty to visit the local schools regularly to supervise the continuation of treatment, or to initiate it in new schools. For this purpose he is supplied with a stock of Achromycin ointment by the Kenya Society for the Blind and also with petrol to cover travelling. His transport is provided by the Government or by a local authority.

It will be noted that the locally-based, eye-trained Medical Assistant holds a key position in the scheme. He prepares for the visit of the Unit, he assists the Unit during its visit, and he carries on routine preventive and curative work between visits. In this way he should, over a period of time, be able to exercise considerable influence in his area in the prevention of ocular disease, for he is also taught to emphasize continually in schools and clinics the simple virtue of washing the face.

To return to our typical safari-the Unit will spend a minimum of 2 full working days at one Centre, often more if large numbers of patients attend and particularly if other local medical centres are included in the visit. But usually on the third or fourth day the Unit moves on to the next Centre on the programme, and the whole procedure is repeated.

At the end of 2 weeks the Unit returns to Nairobi. Here the staff become, in practice, supernumerary members of the eye department of the Kenyatta National Hospital-the central Hospital of the country, and assist in the routine work of the department. First, however, they spend a certain amount of time in cleaning up equipment after a safari and in replenishing supplies and preparing for the next visit. They are also entitled to time off duty in recognition of the strain of safari life and absence from home. The medical officer produces a written report on each safari and has to spend time in planning for future safaris. He also keeps in touch by correspondence with the eye-trained Medical Assistants in the field who are expected to send in brief monthly reports on their activities.

During the year of 11 working months, the Unit sees, on average, about 3,000 eye out-patients and operates on about 300 cataracts and 250 bilateral cases of entropion, with some fifty optical iridectomies and other minor procedures. The present routine is not fully established and, in fact, has only been reached during the last year after a good deal of trial and error, for the staff of the Unit had had little previous experience of this type of work, nor had anyone in East Africa previously undertaken to run a Unit permanently in the field. 
On this account, and because these years also cover a period of change following Independence, quite a number of problems were encountered:

(1) After an initial trial period, we discarded the plan of visiting as many districts as possible in Kenya, in favour of the plan of repeated visits to a few chosen districts where there were eye-trained Medical Assistants, or where we knew from experience that there was a good deal of local co-operation and response. In this way the local staff and the public became acquainted with, and co-operated better with the Unit, and preventive measures could be initiated and carried through.

(2) We have tended to concentrate on those areas where the local people respond and have tended to ignore those where, though the incidence of disease may be high, there is little co-operation. This seems to be the right attitude in a situation where eye services fall far short of the need.

(3) Owing to the shortage of government Medical Officers in the districts following Independence, it became clear that it was no longer possible or reasonable to ask the Medical Officers of Health to spend time in the detailed preparations required for our safaris. This preparation is now largely in the hands of the Medical Assistants who have been trained by us. When visiting mission hospitals, we deal direct with the Doctor in Charge. In both cases the Medical Officer of Health is, of course, informed of our visit, since the Medical Assistants work directly under him.

(4) One has come to realize that the value of the Unit lies as much in the support and backing it can give to eye Medical Assistants in the field as in the actual work it does during these visits. While the Unit visits a given area for a few days each year, the Medical Assistant, even when only on part-time ophthalmic work, is constantly present in his area and is able to build up personal local contacts.

A few remarks on the clinical aspects of the work may be of interest.

\section{Trachoma}

As in every tropical country this is a major problem; but the incidence in Kenya varies widely from one locality to another. We determine the local incidence by noting the number of entropion cases seen in a given clinic, and by carrying out school surveys in the same area. In general, we find the accepted picture of heat and dryness coincident with a high incidence of trachoma to be true. But there are at least two notable exceptions to this rule in Kenya. For instance, the Kikuyu have a remarkably high incidence of trachoma for a progressive people, yet they live at an average altitude of $6,000 \mathrm{ft}$ in a temperate climate on the eastern slopes of the Aberdare Mountains where the rainfall is between $30 \mathrm{in.}$ and $70 \mathrm{in}$. Their hygienic standards, however, are generally recognized by other tribes to be low. By contrast certain low lying areas 100 miles east of the Aberdares, both backward, hot, and dry, have a relatively low incidence of trachoma and the children at school appear remarkably clean. It seems, therefore, that local social custom is perhaps the most important factor in determining the incidence of trachoma in Kenya, but it still remains true that the worst areas have a low rainfall; it is on this account that the people are nomads and consequently resistant to change; schools are few, and the adults often quite indifferent to any effort made to help them. It is in these areas where the need is greatest that very little can be done to meet it. However, a beginning has been made in tackling the trachoma problem in general. During the last 9 months the five 
Medical Assistants, working only part-time on eyes, have examined 7,605 school children, 1,907 of whom have been treated for trachoma, and they have also operated on 580 cases of entropion.

\section{Senile Cataract}

This is very common; on average we expect to see one mature cataract for every ten eye-patients if the correct publicity has been carried out. Naturally, bilateral cataracts take priority. In general we do not operate till a cataract is mature and changes have started in the other eye. The Unit has operated on nearly 1,000 patients since it started. The great majority of these are seen either by me or by my Clinical Assistant once after operation; but we have not yet seen a clear case of intra-ocular sepsis. This experience indicates that a high degree of asepsis is achieved during the course of operation in spite of our primitive surroundings. It should of course be borne in mind that simple country people seem to have a higher resistance to many types of infection.

\section{Corneal Opacities}

These are very common, being both traumatic and infective in origin. In practice no treatment is available for such lesions, unless they are bilateral and central, when we do an optical iridectomy. A few of these cases are suitable for corneal grafting, but not infrequently the patients are unwilling to make the journey to Nairobi where keratoplasty can be performed.

One can only speculate on the cause of these opacities for histories are difficult to obtain and often unreliable. Certainly, in dry, thorny country, trauma is one factor, and trachoma is another; but the largest single cause is probably corneal ulceration in childhood following an acute untreated conjunctivitis in malnourished individuals. This may be primary or secondary to measles. In practice, however, we rarely see acute conjunctivitis in childhood while on safari.

\section{Keratomalacia}

This is seen only rarely, at least in its active stage.

\section{Conjunctival Xerosis}

Cases have occasionally been seen in very dry areas at the end of the dry season. It would seem that vitamin A deficiency is not responsible for much blindness in Kenya.

\section{Allergic Conjunctivitis}

This is not unusual, but appears to have a local distribution, some areas being almost free from it. Limbal lesions can, on occasion, be severe, extending onto the cornea in the form of an oedematous pannus. This condition responds to cortisone ointment or subconjunctival cortisone.

\section{Prevention of Blindness}

In general, in the majority of abnormal eyes seen by us the lesions have an infective origin, particularly in the trachomatous areas. Of these eyes, the majority have corneal lesions of one kind or another and little or nothing can be done to improve vision unless 
active trachoma or entropion be present. This means that preventive measures alone are applicable in reducing the incidence of corneal lesions; these, however, are difficult to apply since they require funds and trained personnel, and a fundamentally different attitude by the population to hygiene and disease. For the health of the eyes the chief problem is daily face-washing and the availability of water. Further, once an acutely inflamed eye has developed, the mother of the child, burdened with other household and cultivating duties, often fails to realize the importance of early treatment. Even if she does, the nearest medical centre may be several miles away on foot and it is unlikely that she will be able to make a daily visit. Even if she were to achieve this, it is more than probable that the staff at the centre will only have a nodding acquaintance with ocular problems. It would seem, therefore, that a relatively high incidence of blindness or of defective vision will remain a characteristic of these communities for a long time.

One very common class of patient remains to be mentioned, the youngster of secondary school age complaining of symptoms of eye-strain. Our Unit has to insist on a publicity which frankly discourages these young people from attending; otherwise we find our clinics flooded with anxious young men and women who are quite sure that they need glasses or that they have serious ocular disease, to the detriment of the ordinary out-patients with gross pathological conditions. This problem is more in evidence in the more advanced areas where school attendance is high. A possible, partial and practical solution to this problem may lie with the eye-trained Medical Assistants. In one area, our Medical Assistant holds a special clinic on Saturday morning for school pupils only, there being no school classes on Saturday. He carries out an external examination, examines the fundus with an ophthalmoscope; and assesses the visual acuity with a Snellen chart. Having satisfied himself that there is no serious ocular disease, he informs the patient and explains how the symptoms arise. These are largely due to anxiety over examination results, and the conviction so wide-spread in Africa that the more one reads, the more one learns. The Medical Assistant gives advice on faulty lighting and reading habits, and sends the patient away with a placebo. If the visual acuity is frankly deficient, the patient is sent for refraction; in Kenya this may involve a journey of one or two hundred miles.

\section{Summary}

An account is given of the activities of the Kenya Mobile Eye Unit and of the eye-trained Medical Assistants who carry out preventive and curative work in certain districts in Kenya. Observations on a number of common clinical conditions seen by the Unit are included.

\section{ADDENDUM}

Since this article was accepted for publication, this Mobile Eye Unit has been virtually handed over to the charge of the Clinical Assistant mentioned in the text. He takes full responsibility for every aspect of the Unit's work while on safari, and performs with great skill the intracapsular operation described in the text. He has of course no recognized medical qualifications. 
active trachoma or entropion be present. This means that preventive measures alone are applicable in reducing the incidence of corneal lesions; these, however, are difficult to apply since they require funds and trained personnel, and a fundamentally different attitude by the population to hygiene and disease. For the health of the eyes the chief problem is daily face-washing and the availability of water. Further, once an acutely inflamed eye has developed, the mother of the child, burdened with other household and cultivating duties, often fails to realize the importance of early treatment. Even if she does, the nearest medical centre may be several miles away on foot and it is unlikely that she will be able to make a daily visit. Even if she were to achieve this, it is more than probable that the staff at the centre will only have a nodding acquaintance with ocular problems. It would seem, therefore, that a relatively high incidence of blindness or of defective vision will remain a characteristic of these communities for a long time.

One very common class of patient remains to be mentioned, the youngster of secondary school age complaining of symptoms of eye-strain. Our Unit has to insist on a publicity which frankly discourages these young people from attending; otherwise we find our clinics flooded with anxious young men and women who are quite sure that they need glasses or that they have serious ocular disease, to the detriment of the ordinary out-patients with gross pathological conditions. This problem is more in evidence in the more advanced areas where school attendance is high. A possible, partial and practical solution to this problem may lie with the eye-trained Medical Assistants. In one area, our Medical Assistant holds a special clinic on Saturday morning for school pupils only, there being no school classes on Saturday. He carries out an external examination, examines the fundus with an ophthalmoscope; and assesses the visual acuity with a Snellen chart. Having satisfied himself that there is no serious ocular disease, he informs the patient and explains how the symptoms arise. These are largely due to anxiety over examination results, and the conviction so wide-spread in Africa that the more one reads, the more one learns. The Medical Assistant gives advice on faulty lighting and reading habits, and sends the patient away with a placebo. If the visual acuity is frankly deficient, the patient is sent for refraction; in Kenya this may involve a journey of one or two hundred miles.

\section{Summary}

An account is given of the activities of the Kenya Mobile Eye Unit and of the eye-trained Medical Assistants who carry out preventive and curative work in certain districts in Kenya. Observations on a number of common clinical conditions seen by the Unit are included.

\section{ADDENDUM}

Since this article was accepted for publication, this Mobile Eye Unit has been virtually handed over to the charge of the Clinical Assistant mentioned in the text. He takes full responsibility for every aspect of the Unit's work while on safari, and performs with great skill the intracapsular operation described in the text. He has of course no recognized medical qualifications. 